\title{
Working alongside Andrzej Szczeklik - a lifetime to remember
}

\author{
Ewa Niżankowska-Mogilnicka \\ 2nd Department of Medicine, Jagiellonian University Medical College, Krakow, Poland
}

\section{Corespondence to:}

Prof. Ewa Niżankowska-Mogilnicka, $\mathrm{MD}$, PhD, II Katedra Chorób

Wewnętrznych, ul. Skawińska 8 31-066 Kraków,

e-mail: ewan@ghml.pl

Received: March 262012

Accepted: March 26, 2012

Pol Arch Med Wewn. 2012; 122 (Special Issue): $40-41$

Copyright by Medycyna Praktyczna Kraków 2012
My first meeting with Professor Andrew Szczeklik has remained in my memory to this day. It was a sunny winter day in February 1972. I was just finishing my studies at the Faculty of Medicine, being mainly interested in cardiology and internal medicine in general, and I was looking for a job at the time. Dr Jerzy Szczeklik, now Professor of Cardiology, who was a tutor of our students' scientific group, told me that his brother Andrew was going to obtain a post as Head of the Department of Allergy and Clinical Immunology in Krakow. He strongly advised me to go and meet Andrew at a job interview. "He's an extremely brilliant man" - he said. I already knew that Andrew Szczeklik's scientific interests were very broad, in allergology and cardiology alike, so I decided to see him without any delay. During a one-hour conversation, he asked many questions about my studies, my plans for the future and my scientific interests in cardiology. It was a very friendly meeting.
At the end he said: "Ewa, you can start work here as a volunteer immediately. Then, we'll see.”

A few months later it turned out I was the first assistant he employed after moving from Wrocław to Krakow. Even today there are very few people in Poland who understand medicine as thoroughly as he did, in both general and specialist fields alike. Therefore, I regarded the opportunity to work with him as an intellectual adventure and an extraordinary privilege.

He was a very hard-working and dedicated person, who spent days and nights in the clinic. In addition to imparting his extensive medical knowledge to his students, he also taught us the importance of having empathy and showing compassion when counselling patients, some of whom where on their deathbed.

As a boss, he was extremely demanding, but very helpful and willing to share his knowledge and skills. His interest in our achievements

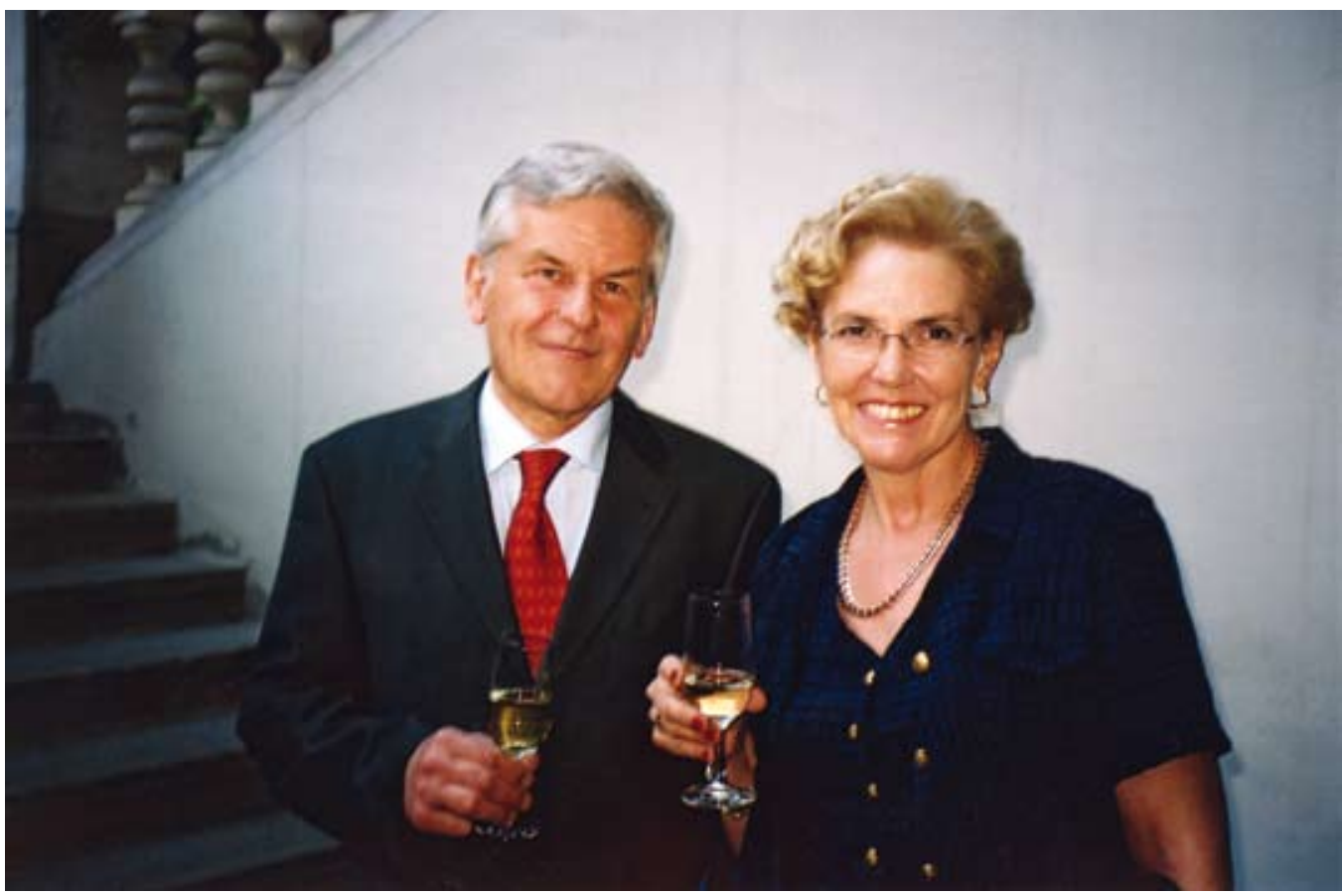

FIGURE 30 Professor Ewa Niżankowska-Mogilnicka and Professor Szczeklik at the Nowodworski College, Jagiellonian University, Krakow, 2000s 


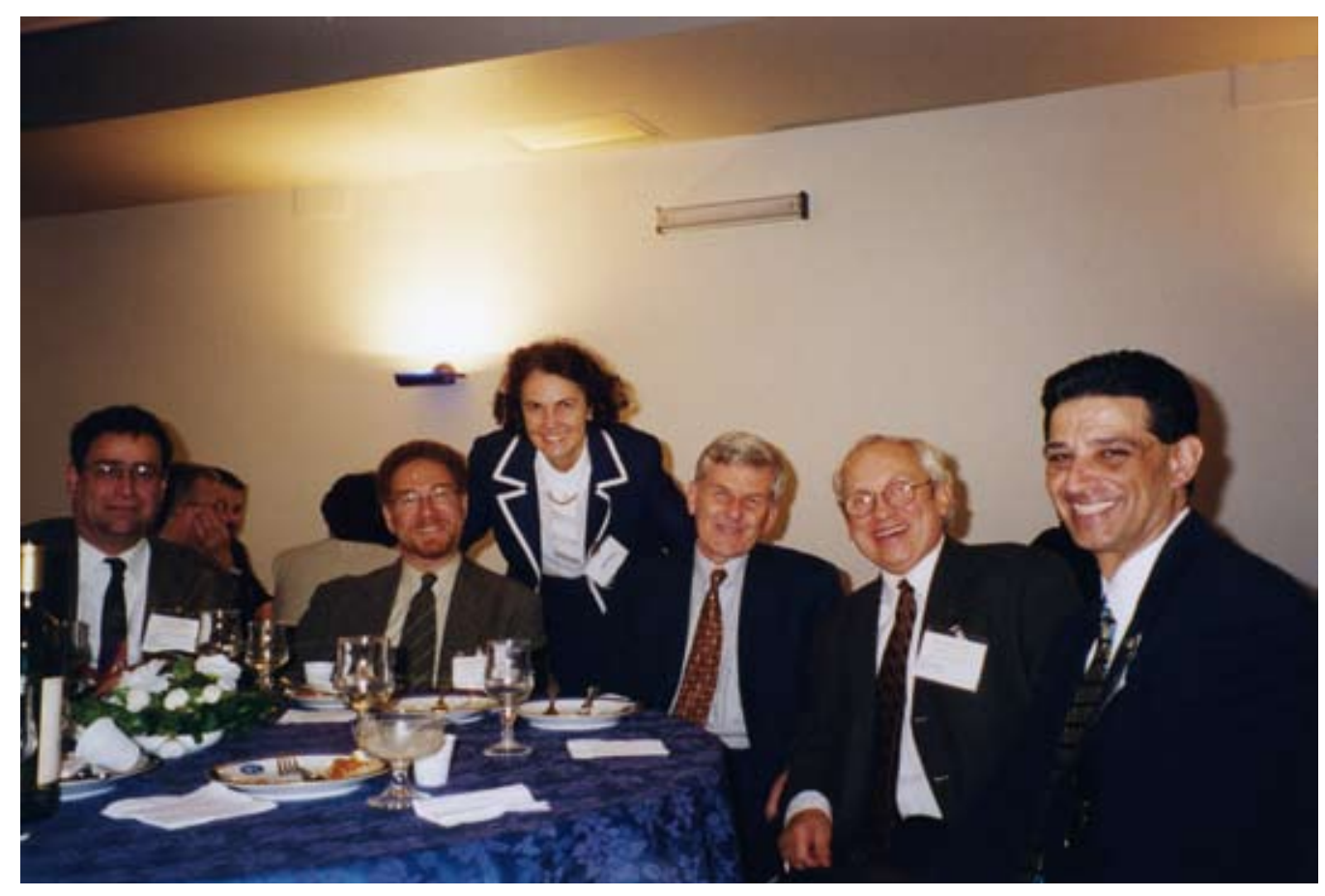

FIGURE 31 At the congress of the American Thoracic Society. From the right: Professor Serham, Professor Jacek Hawiger, Professor Szczeklik, Professor Ewa Niżankowska-Mogilnicka, Professor Judah Denbeurg, United States, 1990s

motivated us to self-development. I had the privilege to publish scientific papers prepared jointly with Professor Szczeklik and to share the research process with him. The professor's great passion for science was coupled with a paradoxical conviction of the frailty of research deliverables and results of our efforts. He knew that due to the progress of science many things we take for granted today will soon be undermined, put in parentheses and replaced by more contemporary, stronger arguments.

Being such an eminent scientist and a man devoted to experiential learning, Professor Szczeklik taught us at the same time that science is only a part of cognitive knowledge, and that medicine based on scientific data does not only rely on rigid observance of guidelines and recommendations. He showed us that patient treatment should be based not only on scientific data and the clinical situation but also on the patient's preferences and system of values and on our individual experience and skills.

Many people consider Professor Szczeklik a humanist since he wrote Catharsis and Kore, two outstanding and beautiful books that touched upon art, music, philosophy, and literature. But for those who knew him better, he was a true humanist mostly because he was unrivalled in incorporating the humanist perspective into medicine in Poland. He viewed illness as a disruption of the cosmic harmony, and ascribed to the physician the role to restore this harmony and to attune the patient to the rhythms of the universe.

For that reason he was trusted by the luminaries of Polish culture. Among his patients were the Nobel Prize winners Czesław Miłosz and Wisława Szymborska, the composer Henryk Mikołaj Górecki, and the journalist Jerzy Turowicz. Ordinary patients wrote him letters of thanks, whilst the artists performed for him at the annual name day ceremony at the Piwnica pod Baranami cabaret.

Almost 40 years passed since my first meeting with Professor Szczeklik and many things have changed. I have become a professor of medicine at the Jagiellonian University and a member of the Polish Academy of Arts and Sciences. A few weeks ago, Professor Szczeklik's health worsened and he was hospitalized in our intensive care unit. I visited him almost every day. We talked about current research programs, future plans, and he felt a little bit better, smiled a lot and he truly believed that he would make a rapid recovery.

The last time I met Andrew was on a sunny day in February. The next day in the morning he died unexpectedly. He left us an unwritten testament not to lose the human perspective in pursuit of scientific facts and not to forget about the soul while trying to heal the body. 